\title{
Human Psychological Characteristics versus Animal Characteristics
}

\author{
Arnulf Kolstad ${ }^{1,2}$ \\ ${ }^{1}$ Norwegian University of Science and Technology, Trondheim, Norway \\ ${ }^{2}$ Hangzhou Normal University (HNU), Hangzhou, China \\ Email: ulfkol@ymail.com
}

Received January 28 ${ }^{\text {th }}$, 2013; revised March $2^{\text {nd }}, 2013$; accepted April $1^{\text {st }}, 2013$

\begin{abstract}
Copyright (c) 2013 Arnulf Kolstad. This is an open access article distributed under the Creative Commons Attribution License, which permits unrestricted use, distribution, and reproduction in any medium, provided the original work is properly cited.
\end{abstract}

\begin{abstract}
The role of biology in psychology changes from animals to humans. Biology determines animal behaviour in natural environments. For humans the biological forces changes to an energizing function. They recede in the background and the higher psychological functions govern consciousness and behavior. Humans do not have to obey the instincts or reflexes, but have the option to do what they decide to do after reflecting on the alternatives. No other species have this ability to the same degree. The difference between Homo sapiens and other species in this regard is not only a distinction in degree it is a distinction in principle. To understand development of language in its relation to thought, consciousness and volatile behavior is essential.
\end{abstract}

Keywords: Biology; Culture; Lower Psychological Functions; Higher Psychological Functions; Cultural Tools; Language; Thought

\section{Introduction}

The role of biology in psychology changes from animals to humans. Biology, instincts and drives determine animal behaviour in natural environments; for human psychological functions and social behaviour biology changes to a potentiating, energizing but not determining function. As Carl Ratner claims, "This is only logical, and it is Darwinian, for we have seen that the fundamental principle of Darwinism is that organismic behavior is a function of environment. Culture is a radically different environment from nature; therefore cultural behavior and its mechanisms must be radically different from natural behavioral mechanisms of animals" (Ratner, 2011). The different role played by biology is not a difference in degree between animals and humans, but in principle, as formulated by Lev Vygotsky and Alexander Luria: "behavior becomes social and cultural not only in its contents [i.e., what we think about] but also in its mechanisms, in its means...A huge inventory of psychological mechanisms - skills, forms of behavior, cultural signs and devices - has evolved in the process of cultural development" (Vygotsky \& Luria, 1930/1993).

The number of human activities under biological control is greatly reduced in comparison with (other) animals. Conscious behaviour is for instance only possible if the instinctive or lower functions characterising animal behaviour are set aside from their original function. The most peculiar aspect of humans compared with other living species is that humans are created by a culture that they have created. Their higher psychological functions are acquired in a human culture using symbols and signs (language). Psychological phenomena, including cognition, emotion, memory, motivation, self-appraisal, and identity are humanly constructed when individuals partici- pate in social interaction.

The instinctive, lower functions operate in different ways from cultural conscious processes and therefore the former cannot govern the latter. The lower functions do not even serve as the basis of the higher functions. The instinctive or elementary functions are actually inimical to cultural conscious processes since they are automatic, mechanical, involuntary, physical processes; which directly impel non-volitional, unconscious behaviour. The division of the pre-social, lower psychological functions from the higher (cultural) ones illustrates the difference between animal and human and defines the human psyche as a special system for conscious, volitional regulation of the behaviour of the human organism whose individual development (unlike the organism of the animal) integrates the biological and the socio-cultural (Kolstad, 2012).

Natural processes operate in hummingbirds, for example, to automatically impel them to fly toward red-coloured flowers; or they impel male dogs involuntarily and mechanically to mount and mate with a female dog that emits a particular scent during the fertile period. Hummingbirds and dogs do not think about what they are doing, they cannot control it, they cannot plan it or imagine it, or remember (relive) it in specific detail; they do not appreciate the object of their behaviour, as a human male appreciates his sexual partner or appreciates a beautiful sunset or a symphony by Beethoven. This is why elementary natural processes cannot determine human psychology in the same way that they determine behaviour of birds and dogs (Ratner, 2011).

The lower psychological functions, those automatic, instinctive kinds of behaviour are non-volitional and uncontrolled by consciousness. To be a human, however, means to reduce the automatic, instinctive behaviour and become a conscious being, able to decide, choose, and think with language as a cultural 
and psychological tool. Humans' higher psychological functions, their language and thinking, have to be the core of human psychology. Scientific psychology cannot ignore the volitional and conscious mind. It has to be a significant topic in psychology.

The distinction between lower and higher psychological functions is described and explained in detail by Vygotsky and the school of cultural historical psychology. Other contributions to a scientific psychology have made this distinction as well. Freud, following Darwin, divided for instance "the brain into 'lower' parts that we share with animals, and that process our brute animal instincts, and 'higher' parts that are uniquely human” (Doidge, 2007: p. 297). Freud believed that civilization rests on the partial inhibition of lower functions such as sexual and aggressive instincts. He also believed we could go too far in repressing our instincts, leading us to develop neuroses (Doidge, 2007).

The tools for the mind, for example language, giving humans the ability to reason and to abstract thinking are situated in and belong to the culture, and they are internalized and become psychological tools during socialization. People in different cultures, with different tools such as different languages also have different higher psychological functions, different perceptions, motivations, emotions, and cognitions. The cultural tools are also making the brain's function and structure. Different cultures create different brains (Kolstad, 2013); in short culture affect everything that psychologists may be interested in.

The architecture of the neuro system in the brain changes with the inclusion of symbols and signs in the psychological repertoire. The brain has to follow the development of the mind assimilating words, concepts and symbols, acquired in communications with others, and has to change its structure and function to represent the sense impressions, the communication experiences and the changing mind. When we learn to read and write our mental, cognitive functions are reorganized and changes even more and the structural and functional brain architecture adapt and adjust as well.

\section{The Cultural-Historical Evolution of the Mind}

The first attempts to approach human mental processes as the products of evolution were taken in the second half of the nineteenth century by Charles Darwin and his successor Herbert Spencer. They both attempted to trace the ways in which complex forms of mental activity develop through the evolutionary process. The evolutionary approach, which was quite valid for a comparative study of development of the lower psychological functions in the animal world, found itself in something of a blind alley when it tried to study evolution of higher psychological functions among humans as a result of natural circumstances. Those functions cannot be explained by natural adaptation or adaption solely to nature. They originated as a result of social, cultural development and adjustment. And definitely not solely by something innate in every human, for instance the genes.

At the beginning of the present century, the French socialogist and social psychologist Emile Durkheim assumed that the basic processes of the mind are not manifestations of the spirit's inner life or the result of natural evolution, but rather originated in humans as a result of the created culture or society (Durkheim \& Mauss, 1963). Durkheim's ideas formed the basis for a number of other studies, in which the French psychologist Pi- erre Janet and others played a prominent part. The French school of sociology, however, had shortcomings that invalidated its theories. It refused to interpret the influence of society on the individual mind as the influence of the cultural and social system and the actual forms of social activity on individual consciousness. Unlike the approach of cultural-historical psychology, the French school considered this process only as an interaction between "collective representations" or "social consciousness" and individual consciousness, all the while paying no attention to particular social systems, culture or practices (Luria, 1976).

In Russia in the beginning of the $20^{\text {th }}$ century humans were understood and studied as determined by reflexes, reactions and associations with little room for subjectivity, agency and creativity. Vygotsky asserted, however, that a scientific psychology cannot ignore that human consciousness exists and that it has to be a significant topic in psychology (Vygotsky, 1931/1997). Humans' higher psychological functions, their language and thinking, have to be the core of human psychology. Humans have many psychological functions in addition to the ones we find in dogs and other living organisms. Most basic is the fact that man not only develops (naturally); he also constructs himself. The number of human activities under biological control is greatly reduced in comparison to animals. Psychological phenomena, including perception, cognition, emotion, memory, psychopathology, personality and malfunctions are humanly constructed as individuals participate in social interaction. This position, that psychology has a constructed character, does not disregard biological influences.

\section{Evolution Made Us for Culture}

The higher-order functions became, however, a possibility since natural evolution made thinking and language appropriation possible, and because we established human cultures which developed higher psychological functions in each individual whatever culture they were born into (Fiske et al., 1998). When human beings participate in social interactions and employ cultural and psychological tools, for instance language and other signs, they develop, construct and create their higher psychological functions, ways of thinking, feeling, remembering, their sensation and perception. These higher functions are not natural or innate processes in human adults as the lower functions are in animals and human neonates. "Most basic is the fact that man not only develops (naturally); he also constructs himself" (Vygotsky, 1989: p. 65). Therefore there are qualitative differences between the psyche of humans and that of animals. Unlike animals the key to human's psychological functions is sociogenesis, the transformation of social relations, through interiorization, into the individual's psychological functions.

Kono (2010) also refers to the creation of human culture when he comments on the qualitative discontinuity between human beings and animals, referring to Merleau-Ponty. He does not, however, go into details about what is the essence of humanity that distinguishes human beings from other animals except for mentioning that human beings have collectively changed their environment, much more than other animals have done and created a human culture: Humans make "unaccountably various kinds of tools, raise animals, cultivate the fields, plant vegetables, construct houses, buildings, monuments, villages and cities, make social systems such as government, law, economy, intellectual and communicative tools such as language, charac- 
ters, signs, symbols, calculators, books, libraries, arts, mass medias, and so on" (Kono, 2010: p. 334).

Also according to Cole (2002) there is an important differrence between humans and other living organisms in their relation to the environment. While most organisms adapt and do not affect to any great extent their environment, humans create to a certain degree the cultural, social (and partly physical) environment they experience and are affected by. Biology therefore changes its role in behavior from animals to humans." ...the struggle for existence and natural selection, the two driving forces of biological evolution within the animal world, lose their decisive importance as soon as we pass on to the historical development of man. New laws, which regulate the course of human history and which cover the entire process of the material and mental development of human society now take their place” (Vygotsky, 1994: p. 175).

The specific interpretation of the empirical evidence of relationship between mind, brain and culture is colored by a more general view on the nature of the human species and especially the importance of the genetic outfit and culture respectively. This is well known as the "nature and nurture dichotomy". This old discussion about the influence from nature (biology) and culture is a result of the fact that humans from different cultures are universal and unlike at the same time.

\section{The History and Origin of Homo sapiens}

The universal behaviour that defines human beings arises from our biological similarity. In some way we are all Africans (Shipman, 2003) since the first Homo sapiens lived in Africa. Researchers studying human origins do not, however, quite agree when and in what shape the homonids left Africa. According to the Multiregional Continuity Model, Homo erectus left Africa 2 mya (million years ago) to become Homo sapiens in different parts of the world (Myers, Abell, Kolstad, \& Sani, 2010). The "Out of Africa Model" claims that Homo sapiens evolved relatively recently in Africa and migrated into other parts of the world to replace other hominid species, including Homo erectus (Johanson, 2001). In response to climate change and the availability of food, those early hominids migrated across Africa into Asia, Europe, the Australian subcontinent and, eventually, the Americas. As they adapted to their new environments, early humans developed differences that, measured on anthropological scales, are relatively recent and superficial. For example, those who stayed in Africa had darker skin pigment, a "sunscreen for the tropics" (Pinker, 2002) and those who went far north of the equator evolved lighter skins capable of synthesizing vitamin D in less direct sunlight.

We were Africans recently enough that "there has not been much time to accumulate many new versions of the genes" (Pinker, 2002: p. 143). Biologists who study our genes have found that we humans are strikingly similar in genes, like members of one tribe. We may be more numerous than chimpanzees, but chimps are more genetically varied. We also share the majority of our genes with other species, for instance mice (Myers, Abell, Kolstad, \& Sani, 2010).

\section{Cultural Diversity}

The diversity of humans' languages, customs, and expressive behaviors confirms that much of our behaviour is socially and culturally programmed, not hardwired in the genes. Humans, more than any other animal, harness the power of culture to make life better. We have culture to thank for our communication through language. Culture facilitates our survival and reproduction, and nature has blessed us with a brain that, like no other, enables culture. No species can accumulate progress across generations as smartly as humans due. We can pass our experiences and transmit information and innovations across time and place to the future generations in a unique way, by written language (Myers, Abell, Kolstad, \& Sani, 2010).

We needn't think of evolution and culture as competitors. Cultural norms subtly but powerfully affect our attitudes and behaviour, but they don't do so independent of biology. Advances in neuroscience indicate that experience and activity change the brain and establish new connections between neurons (Quarts \& Sejnowski, 2002). Due to its plasticity the brain develops and increases its capacity, and the culture puts its special marks on its structure and changes its function.

\section{Phylogenetic and Ontogenetic Development}

The phylogenetic development of humans followed the principle of natural evolution. During this evolution humans acquired the possibility of speech and thought owing to the increased size of the brain and the voice-tube. These two abilities, language and thought, were combined at a certain stage of development and the language ability combined with thinking initiated a new era for humans: the cultural era, where psychological functions were no longer dependent to the same degree on the lower instinctive reactions. Gradually consciousness developed so that the instinctive biological forces were set aside. The acquired abilities changed human's further development radically.

Relevant to the phylogenetic aspect is that in the transition from animal to human a change occurred in the relation between the individual and the environment. Animals adjusted to their environment by means of evolution. Humans, on the other hand, adjust to their environment by acting on it and changing it. In the transition from animal to human there is an emergent property in relation to psychological functioning. Humans learn to reflect and control their own mental processes, yielding higher psychological functions which are absent in animals. Intimately involved in this control of one's own psychological processes are the emergence of cultural/psychological tools and the mediation of psychological functioning by means of them (Pick \& Gippenreiter, 1994).

The higher-order functions became a possibility since natural evolution made thinking and language appropriation possible, and because we established human cultures which developed higher psychological functions in each individual. When human beings participate in social interactions and employ tools, for instance language and other cultural signs, they develop, construct and create their higher psychological functions, ways of thinking, feeling, remembering, their sensation, perception and communication.

Evolutionary biologists have for many years discussed the reason why Homo sapiens became a new species so different from its animal ancestors. Most often they have looked for anatomical or morphological characteristics, for instance the size of the brain, the functional benefits due to bipedalism, i.e. the ability to move on two legs, or the hand with opposable thumb able to seize (Kolstad, 2010). The unique ability to use language and symbolic systems were hardly mentioned by the biologists. Focusing intently on biological changes they do not 
refer to culture as a cause of selection. Because of this the evolutionary biologists did not analyze the relationship between biological and cultural development (deLima, 1997) and they missed the most important for developing Homo sapiens: the voice tube. The Neanderthals, in many ways similar to Homo sapiens from a biological point of view, did not develop in the same way. They lacked the voice-tube and could not develop spoken language as did Homo sapiens.

Although the voice-tube had some biological drawbacks, for instance increased exposure to choking and less effective chewing (Lieberman, 2006) it represented an enormous enhancement in flexibility concerning production of sounds, and therefore an improvement of communication. This benefit meant the start of human beings with higher psychological functions as we know them today.

\section{Language as a Cultural/Psychological Tool}

With language and the substantial growth in brain size an accelerated change began. Humans developed the ability to think using a language, written language, rituals and arts. From a biological and anatomical point of view however, we are in principal similar to our ancestors 200,000 years ago. In a cultural and psychological sense however, there are such huge differences from our ancestors that it cannot be explained by biological adaption (Kolstad, 2010). To explain radical changes in humans the importance of language and other cultural and psychological tools have to be accepted as a major contribution to human development and higher psychological functions. Vygotsky said that the greatest drama of ontological development was played out in the very first words of a child-this period illustrates and represents the conflict between the natural and the socio-historical. Penetration of the plot of that drama and its motive forces led Vygotsky to his principal theory: the theory of the development of the higher psychological functions (Yaroshevsky, 1989).

\section{Human Language}

No other specie has a language like the human language. Vocal reactions in animals are not connected with intellectual reactions, i.e., with thinking. It originates in emotion and is clearly a part of the total emotional syndrome, but a part that fulfills a specific function, both biologically and psychologically. It is far removed from intentional, conscious attempts to inform or influence others. In essence, it is an instinctive reaction, or something close to it. For humans language is something else than an instinctive, emotional reaction. It is objective and social, connected to thinking and the correspondence between thought and speech characteristic of man is absent in (other) animals. Thought and language have different genetic roots and the two functions develop along different lines and independently of each other up to a certain age, about 3 years. The close correspondence between thought and speech that characterizes man from about 3 years of age is absent in animals. "(T)he most significant moment in the course of intellectual development, which gives birth to the purely human forms of practical and abstract intelligence, occurs when speech and practical activity, two previously completely independent lines of development, converge" (Vygotsky, 1978: p. 24).

Language is not created by the subject. It exists independently of it. The task with which the subject is concerned is the use of a ready-made sign system (not one she/he creates on his own) in communication, cognition or action in the surrounding world. We often hear that "language is a tool of thought". This is a familiar expression among psychologists but language is much more than a tool for thought. The word also has a volitional function. Humans' locomotive apparatus is subordinate to it. The word has power over the real actions of humans' bodily structure and their psychological functions (Yaroshevsky, 1989). Literacy and the written language has contributed to human development and made Homo sapiens different from all (other) animals.

What had been a natural evolution of Homo sapiens has become a cultural evolution for every individual. Human culture influences every individual's psychology and biology (especially the brain), and culture creates higher psychological functions, i.e. human perception, cognition, memory, motivation, emotions etc., all the functions with which psychologists deal.

\section{Communication among Animals and Humans}

Animal's communication is different from human communication: "Nonhuman primate communication consists of natural bodily and vocal expressions in direct response to events. These expressions, in turn, directly stimulate behavioral responses in other members of the species. Such biological reactions contrast with human communication which consists of invented sounds that express symbolic concepts about things human words cognitively mediates rather than being immediate by-products of them” (Geertz, 1966: pp. 25-26). Drummond puts it this way: "Words are conventional, movements and sounds are natural” (Drummond, 1894: p. 208).

From the very beginning a child is led along the path of psychological development by adults. Communication serves as a necessary condition for each new turn of a child's thought. Communication assumes understanding, and the instrument of understanding is the word. The word's "adult" meaning, however, cannot be poured into the head of a little child together with the sign of the language; the words meaning will change during development and new words or concepts develop understanding and enter into new connections, and knowledge and understanding increase with the relation the word enters into.

.... “animals' natural dispositions can be elicited by crude communicative acts because the organism already knows what to do. Human communication, in contrast, must tell the individual what to do and how to do it, because he has no biological guidance” (Geertz, 1966: p. 30).

One of Vygotsky's main hypotheses was that cultural factors and cultural operating mechanisms elevate and expand consciousness beyond animal consciousness (Ratner, 2011). Human consciousness is more agentive since it is dependent on a human shaped culture and not on biological mechanisms. Being a socially constructed phenomenon and possessing cultural features and mechanisms, psychology cannot logically be simultaneously governed, by natural, biological processes (Ratner, 2011). Biology has lost its determining function in human behaviour. To live in a human constructed culture calls for socially constructed, designed, voluntary, changeable behaviour. Culture determines the form, content, and conditions of behaveiour. In contrast, the form, content, and conditions of animal behavior are determined by natural, biological elements. Elementary, natural mechanisms are antithetical to cultural-psychological mechanisms and features. Biological processes and lower, elementary psychological functions therefore have to recede 
into the background as a general potentiating substratum of behaviour (Ratner, 2011). The driving forces of biological evolution within the animal world lose their decisive importance as soon as we pass on to the historical development of man. New laws regulating the course of human history which cover the entire process of the material and mental development of human society now take their place (Vygotsky \& Luria, 1930/ 1993). Because "this auxiliary stimulus possess the specific function of reverse action, it transfers the psychological operation to higher and qualitatively new forms and permits humans, by the aid of extrinsic stimuli, to control their behavior from the outside. The use of signs leads humans to a specific structure of behavior that breaks away from biological development and creates new forms of culturally-based psychological processes" (Vygotsky, 1978: p. 40).

The biological and elementary functions have not disappeared but they have changed their function and importance as they mingle with higher cultural functions. There is inter-functionality between the organic maturation and cultural learning which characterizes the merging and the development of a child into a culture. Cultural learning and the acquisition of cultural tools involve a fusion with the processes of organic maturation. The two contributions to development- the natural and the cultural-coincide and mingle with one another; they penetrate one another and essentially form a single line of sociobiological formation of the child as a cultural human being, developed from a biological being (Vygotsky, cited in Wertsch, 1985: p. 41).

Humans capacity or requirement to acquire culture make human social in a sense that is different from the sociability of other species and explain the new principles of development which appear once a child is born (Cole, 2002).

\section{Thought and Language}

As mentioned in the preceding there are qualitative differrences between the psyche of man and that of (other) animals. The key to man's psychological functions is cultural- and social-genesis, the transformation of culture and social relations, through interiorization, into the individual's psychical acts and with language the most important cultural and psychological tool. We do not find this language mechanism in animals since they do not have the biological prerequisites, the brain and the voice tube nor a culture maintaining a language. Animals are not able to think using a language and therefore not able to develop higher psychological functions in the same way as humans. Language and thought have a particular significance in humans. They stand in a dialectical relationship and constitute each other reciprocally in an internal unity. Language objectifies, completes, and informs thought just as thinking creates language and produces its meaning (Ratner, 1991). "The two processes manifest a unity but not an identity" (Vygotsky, 1987: p. 280). "Speech does not merely serve as the expression of developed thought. Thought is reconstructed as it is transformed into speech. It is not expressed, but completed in the word" (Vygotsky, 1987: p. 251). Thought development is determined by language, i.e., by the linguistic tools of thought and by the sociocultural experience. The child's intellectual growth is contingent on his mastering of the social means of thought, that is, language. How it develops is one of the most complex problems in psychology. To solve this puzzle mean to explain a vital psychological function in humans.
The relation between thought and speech undergoes many changes. Progress in speech and progress in thought are not parallel. The meanings of words are not a constant. Words undergo evolution especially during childhood but also in adulthood, and an important task is to describe and define the basic steps in that evolution. For instance to uncover the singular way in which the child's "scientific" concepts develop, compared with his spontaneous concepts, and also formulate the laws governing their development means to reveal human development. To demonstrate the specific psychological nature and linguistic function of written speech in its relation to thinking is also an essential task together with clarifying the nature of inner speech and its relation to thought.

\section{Conclusion}

Biological determinism or reductionism cannot explain human emotions and behaviour since all higher psychological functions characterizing humans are culturally created. Hormones are for instance involved in all kinds of love, but only as energizing mechanisms, The behavior, thoughts, feelings, and experiences of love is culturally determined and variable and not biologically determined as in animals. Biology has lost its determining function in human behavior, which is only "natural” given the unique cultural environment in which people live. Culture determines the form, content, and conditions of behavior. In contrast, the form, content, and conditions of animal behavior are determined by natural, biochemical elements (Ratner, 2011). Psychology involves and includes natural, biological processes, such as neuronal and hormonal activity, just as it involves breathing air.

Culture determines the form, content, and conditions of behaviour for humans. In contrast, the form, content, and conditions of animal behavior are determined by natural, biological elements. Elementary, natural mechanisms are antithetical to cultural-psychological mechanisms and features. The driving forces of biological evolution within the animal world lose their decisive importance as soon as we pass on to the historical development of man. New laws regulating the course of human history which cover the entire process of the material and mental development of human society now take their place (Vygotsky \& Luria, 1930/1993).

\section{REFERENCES}

Cole, M. (2002). Culture and development. In H. Keller, Y. H. Poortinga, \& A. Schölmerich (Eds.), Between culture and biology. Perspectives on ontogenetic development (pp. 303-319). Cambridge: Cambridge University Press.

deLima, S. G. (1997). Will adding halves make a whole? Comments on Ratners “Activity as a key concept for cultural psychology”. Culture and Psychology, 3, 195-210. doi:10.1177/1354067X9700300206

Doidge, N. (2007). The brain that changes itself. New York: Viking Penguin.

Drummond, H. (1894). The ascent of man. London: Hodder and Stoughton.

Durkheim, E., \& Mauss, M. (1963). Primitive classification. London: Cohen and West.

Fiske, A. P., Kitayama, S., Markus, H. R., \& Nisbett, R. E. (1998). The cultural matrix of social psychology. In D. T. Gilbert, S. T. Fiske, \& G. Lindzey (Eds.), Handbook of social psychology (pp. 915-981). New York: McGraw-Hill.

Geertz, C. (1966). Religion as a cultural system. In M. Banton (Ed.), Anthropological approaches to the study of religion (pp. 1-46). Lon- 


\section{A. KOLSTAD}

don: Tavistock.

Johanson, D. (2001).

http://www.actionbioscience.org/evolution/johanson.html

Kolstad, A. (2010). Time for paradigmatic substitution in psychology. What are the alternatives? Integrative psychological behavioral science, 44, 58-64. doi:10.1007/s12124-010-9114-y

Kolstad, A. (2012). Inter-functionality between mind, biology and culture: Some epistemological issues concerning human psychological development. In M. L. Seidl-de-Moura (Ed.), Human Development —Different perspectives (pp. 19-41). InTech. doi:10.5772/37595

Kolstad, A. (2013). Epistemology of psychology—A new paradigm: The dialectics of culture and biology. Hauppauge New York: Nova Science Publishers.

Kono, T. (2010). The "extended mind” approach for a new paradigm of psychology. Integrated Psychological Behavior, 44, 329-339. doi:10.1007/s12124-010-9128-5

Lieberman, P. (2006). The evolution of human speech. Its anatomical and neural bases. Current Anthropology, 48, 39-66. doi:10.1086/509092

Luria, A. R. (1976). Cognitive development its cultural and social foundations. Cambridge, Massachusetts \& London: Harvard University Press.

Myers, D., Abell, J., Kolstad, A., \& Sani, F. (2010). Social psychology. New York: McGraw Hill.

Pick, H. L., \& Gippenreiter, J. B. (1994). Encyclopedia of human intelligence. New York: Maxwell Macmillan International.

Pinker, S. (2002). The blank slate: The modern denial of human nature. New York: Viking; London: Penguin.
Quartz, S. R., \& Sejnowski, T. J. (2002). The neural basis of cognitive development: About how we become who we are. New York: Harper-Collins.

Ratner, C. (1991). Vygotsky's sociohistorical psychology and its contemporary applications. New York: Plenum Press.

Ratner, C. (2011). Macro-cultural psychology. In J. Valsiner (Ed.), Oxford handbook of culture and psychology. Oxford: Oxford University Press.

Shipman, P. (2003). We are all Africans. American Scientist, 91, 496499.

Vygotsky, L. S., \& Luria, A. (1930/1993). Studies on the history of behavior. Ape, primitive, and child. Hillsdale, NJ: Erlbaum.

Vygotsky, L. S. (1931/1997). The history of the development of higher mental functions. In R. W. Rieber (Ed.), The collected works of L. S. Vygotsky (pp. 1-252). New York: Plenum Press.

Vygotsky, L. S. (1978). Mind in society. The development of higher psychological processes. Cambridge: Harvard University Press.

Vygotsky, L. S. (1987). Collected works. New York: Plenum Press.

Vygotsky, L. S. (1989). Thought and Language. Cambridge: Massachusetts: MIT Press.

Vygotsky, L. S. (1994). The socialist alteration of man. In R. Van der Veer, \& J. Valsiner (Eds.), The Vygotsky readet (pp. 175-184). Oxford: Blackwell.

Wertsch, J. V. (1985). Vygotsky and the social formation of mind. Cambridge, MA: Harvard University Press.

Yaroshevsky, M. (1989). Lev Vygotsky. Moscow: Progress Publisher. 